\title{
New Testament textual criticism for non-textual critics - A few suggestions
}

J. H. Petzer en G. J. C. Jordaan

The need arises now and again for a translator or an exegete with only a basic knowledge of textual criticism to examine a textual problem in order to verify the reading of the text with which he works. In many such instances the translator or exegete feels himself not capable to do so because of the many difficulties of text-critical methodology, and therefore does not even attempt to fulfil his need. In order to enable such non-textual critics to work with the text at least on a very basic level. we adapted text-critical methodology and rewrote it in a few simple steps. We found the following procedure useful.

\section{STEP 1: REDUCE THE VARIATION-UNITS TO BE EXAMINED}

It is not necessary to examine all the variation-units in the text which you used as the basis of translation, since most of the variation in the manuscripts concerns minutiae which do not make a difference to translation or exegesis. Only the most important variation-units need to be examined. The following may be taken as a guide for the selection of the relevant variation-units:

(1) Use the third corrected edition of the United Bible Societies Greek New Testament (UBS3c)' as the basis for the examination of textual problems and examine only variation-units in the apparatus of this text, since the apparatus was designed to contain those readings which directly affect translation.

(2) Examine only those varation-units which are marked by a $[\mathrm{C}]$ or [D] in the critical apparatus of UBS3c. The evaluation-system in the text was designed to aid the user of the text in telling him what the certainty level of the editorial committee was that the reading they chose, is the original: $\{A\}$ is used to indicate a high degree of certainty, $\{B\}$ a relative degree of certainty, $\{C\}$ a relative degree of uncertainty and $\{D\}$ a high degree of uncertainty. Thus, by reducing the variation-units to be examined to readings marked $\{C\}$ and $\{D\}$, time will not be wasted on the unnecessary examination of textual problems.

(3) Reduce the variations further by not examining all the $\{C\}$ - or $\{D\}$ marked readings, but only those in which your are for some reason particularly interested (for instance those that ought to be discussed in the footnotes of a translation or those which affect an important aspect of the exegesis).

(4) Still further reduction can take place by examining only those variation-units upon which the scholarly world does not agree. For this, the evidence of other published texts of the New Testament, representative of the other main methodological orientations in New Testament textual criticism should be obtained. We suggest the Greek New Testament According to the Majority Text (GNTMT) ${ }^{2}$ as representative of the Majority text methods, and the Greek-English Diglot (Diglot) ${ }^{3}$ as representative of the thoroughgoing eclectic method. 


\section{In die Skriflig}

The rules to follow in using these texts are as follows:

$\star$ If the three texts agree (as in Lk $8: 44$ ), there is no need to continue the examination of the textual problem, since different methodologies of textual criticism agree as to the original reading.

$\star$ If only one of the other texts agrees with the reading of UBS3c (as in Mk 1: 1 or Lk 24:53), you might choose not to continue with the examination of the textual problem (this will in particular be the case if the other text is the Diglot, since this would supply additional internal evidence), or you could go on to the next step.

$\star$ If both the other texts agree against UBS3c (as in Jn $7: 8$ ), or if neither one agrees with the other (as in 1 Cor $13: 3$ ), then go on to the next step.

\section{STEP 2: REDUCE THE VARIANTS WITHIN THE CHOSEN VARIATION-UNITS}

After the reduction of the variants to those which are labelled by the UBS editorial committee as being rather uncertain and those upon which no other method agrees, reduce the number of variants in the variationunit:

(5) Discard those readings which do not occur in Greek manuscripts. In Luke 22: $17-20$, for example, no less than six variant readings occur in the apparatus of UBS3c. Only two, the traditional long reading and the short reading which omits vs. $19 b-20$, need to be examined for the purpose of this method, since the other four do not occur in any Greek manuscript.

(6) Identify the main problem in the variation and attempt to solve this problem before attending to the minute differences between the variants. In Jn $3: 13$ it is clear, for example, that one can distinguish between

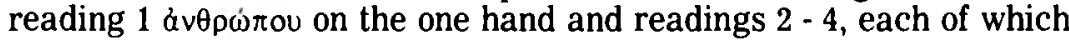
has some (parallel) extending phrase more or less equivalent to "who are in heaven" attached to a $v \theta \rho \omega \tilde{\pi}$ ov. If one decides that reading 1 is the original, one would not have wasted time in examining the other three readings individually. On the other hand, if one should choose for the longer reading in this instance, one may either choose one of the remaining readings (if doing a literal translation for example), which makes further examination necessary, or one might not find it necessary to choose between the three readings at all, if, for instance one is paraphrasing - in which case one again would have saved some precious time by not attending to all the readings individually.

After this reduction of the variants, which will normally leave only one or two readings (or groups of readings) to be examined, you might find that the problem is really not as serious as it appeared at first sight, because one of the readings might be an isolated variation occurring in only one or two late minuscules, in which case you will immediately choose the rival without any further attention to the problem. If not, go on to step 3.

\section{STEP 3: EXAMINE THE EVIDENCE}

The first two steps represent the reduction of the problem to those variation-units and variant readings which are relevant for the purpose of examination. One might find that the application of these principles often solves the problem and makes it unnecessary to examine the text- 
critical evidence as such, If, however, you are not satisfied with the results obtained in steps 1 and 2, examine the evidence:

(7) Examine external evidences. The purpose of the examination of external evidence is to determine which reading has history on its side. Determine (a) which reading is attested by the oldest manuscripts; (b) which reading is attested by the best manuscripts; and (c) which reading has the widest geographical distribution. The following tables might help one to analyse this:

Table A: Date

\begin{tabular}{|l|l|l|l|}
\hline & Reading 1 & Reading 2 & Reading 3 \\
\hline 3rd cent & & & \\
\hline 4th cent & & & \\
\hline 5th cent & & & \\
\hline
\end{tabular}

Table 2: Genealogy and geographical distribution

\begin{tabular}{|l|l|l|l|}
\hline & Reading 1 & Reading 2 & Reading 3 \\
\hline Alexandrian & & & \\
\hline Caesarean & & & \\
\hline Western & & & \\
\hline Byzantine & & & \\
\hline
\end{tabular}

The completion of these tables gives and immediate view of which reading satisfies the three principles given above. John $3: 13$ is a good example. (Since this is only an example, we will only discuss two

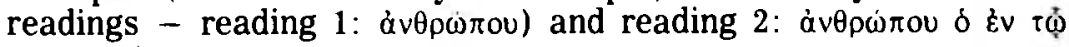

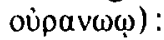

Table 1: Date

\begin{tabular}{|l|l|l|}
\hline & \multicolumn{1}{|c|}{ Reading 1 } & \multicolumn{1}{c|}{ Reading 2 } \\
\hline 3rd cent & $\rho^{66} \rho^{7 \mathrm{~s}}$ cop $^{\mathrm{sa}}$ & \\
\hline 4th cent & $\times \mathrm{B}$ cop $^{\mathrm{bo}}$ & it $^{\mathrm{a}} \mathrm{vg} \mathrm{cop} \mathrm{p}^{\mathrm{bo}}$ \\
\hline 5th cent & & $\mathrm{A}$ it syr \\
\hline
\end{tabular}

Table 2: Genealogy and geographical distribution

\begin{tabular}{|c|c|c|}
\hline & Reading 1 & Reading 2 \\
\hline Alexandrian & $\begin{array}{l}\text { * B L } 33 \text { cop Origen } \\
\rho^{66} \rho^{75}\end{array}$ & 28 cop \\
\hline Caesarean & Didymus Cyril & $\begin{array}{l}\Theta f^{\prime} f^{\prime 3} \\
565700 \text { syr arm geo } \\
\text { Didymus Cyril }\end{array}$ \\
\hline Western & Diat & $\begin{array}{l}\text { it vg Diat Lucifer } \\
\text { Hippolytus Hilarius } \\
\text { Dionysius }\end{array}$ \\
\hline Byzantine & eth & A Byz Lect \\
\hline
\end{tabular}




\section{In die Skriflig}

It is easy to conclude from these tables that Reading 1 occurs in the oldest available manuscripts (read from table 1) and in the best documents (read from table 2). The two readings were, however, more or less equally distributed (read from table 2 ). If the three kinds of external evidence are in agreement, you need not investigate any further. If they differ, or if for any reason you are not convinced by the results of external evidence, go on to (8) below.

(8) Examine intrinsic evidence. Determine which reading is (a) in accordance with the style of the author and (b) best fits into the context. If satisfied that the results of intrinsic evidence are strong enough, no further examination of the problem is needed. If not, go on to (9) below. A useful guideline is the following:

(a) If external and intrinsic evidence correspond, it might not be necessary to continue with the textual examination.

(b) If external and intrinsic evidence should differ, but the one seems strong enough to overrule the other it is also not necessary to continue, though it might be a good idea to get some additional evidence.

(c) If external and intrinsic evidence differ to such an extent that it is impossible to choose the one above the other, go on to (9) below.

(9) Examine transcriptional evidence by determining which reading explains the origin of the rivals best.

To examine this kind of evidence one should know what causes of corruption there were in the history of the text's. One will then attempt to identify which of those causes are at stake in the variation-unit which is being examined, and what influence they might have had on its transmission. On this basis, the reading which best explains the origin of the others, in other words, where the probability of it having originated from the other readings due to a scribal error of some kind is least probable, should be chosen as the original.

At this stage on should be satisfied and convinced about which reading is probably the original. As has been stated above, it might very often not be necessary to go even this far. However, if you are for some reason still not satisfied, you might as a final solution resort to a few stringent criteria.

(10) Hopefully it is never necessary to reach this stage in the text-critical examination, since criteria which are applied mechanically seldom offer convincing evidence. However, it might be and it indeed happens that one has to resort to such criteria in deciding between variant readings. If necessary then, the following criteria are useful:

(a) Choose the reading of the oldest papyri or $x$ and $B$.

(b) Choose the shorter reading.

(c) Choose the more difficult reading.

(d) Choose the least harmonious reading.

(e) Choose the non-Attic reading

TO SUMMARIZE

Step 1: Reduce the variation-units to be examined by

(1) using UBS3c as the source of examination of textual problems;

(2) examining only those variation-units marked by $\{C\}$ or $\{D\}$ in the 
apparatus of UBS3c;

(3) examining only those variation-units which are relevant for the purpose of examination; and

(4) examining only those variation-units about which the scholarly world disagrees.

Step 2: Reduce the variants within the chosen variation-units by

(5) examining only those variants which occur in Greek manuscripts; and

(6) solving the main problem before attending to minutiae.

Step 3: Investigate the evidence by

(7) examining external evidence;

(8) examining intrinsic evidence;

(9) examining transcriptional evidence; and

(10) applying a number of criteria mechanically.

\section{NOTES}

1. K. Aland, M. Black, C. M. Martini, B. M. Metzger \& A. Wikgren (eds.). The Greek New Testament. United Bible Societies 1983. (3rd. cor. ed.).

2. Z. C. Hodges, \& A. L. Farstad (eds.). The Greek New Testament According to the Majority Text Nashville. 1982.

3. G. D. Kilpatrick, (ed.). A Greek-English Diglot for the use of translators. London. 1961. Unfortunately this text is not generally available and only the texts of the Gospels, the General letters, the Pastoral letters, Romans and the two Corinthian letters were completed by prof. Kilpatrick. One therefore has to resort to some other text to get other information. One might consider Tasker's text as alternative, cf. R. V. G. Tasker. (ed.). The Greek New Testament. London. 1964.

4. For the purpose of examining external evidence and also the intrinsic and transcriptional evidence the Textual Commentary is a more than useful tool. cf. B. M. Metzger, A Textual commentary on the Greek New Testament. United Bible Societies. 1971. For discussions on the theory of external and internal evidence, $\mathrm{cf} . \mathrm{K}$ Aland \& B. Aland Der Text des neuen Testaments. Deutsche Bibelgesellschaft. 1982. p. $57 \mathrm{ff}$ and p. $282 \mathrm{ff} ;$ B. M. Metzger. The text of the New Testament. New York. 1968 (2nd. ed.). p. 207 ff; B. M. Metzger, A Textual Commentary on the Greek New Testament. United Bible Societies. 1971. p. xxv ff; J. K. Elliott. The Greek text of the Epistles to Timothy and Titus Salt Lake City. 1968. Studies and Documents. 36. p.1 - 11 .

5. Metzger offers a thorough discussion of the causes of corruption in the manuscripts of the Greek New Testament in B. M. Metzger. The Text of the New Testament. New York. 1968. (2nd. ed.). p. $186-206$. 